\title{
Análise do crescimento das empresas de base tecnológica no Brasil
}

\author{
Daniela Tatiane dos Santos ${ }^{\mathrm{a}, *}$, Marcelo Pinho \\ a,*dtatiane@dep.ufscar.br, UFSCAR, Brasil

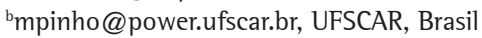

\begin{abstract}
Resumo
As empresas de base tecnológica (EBTs) são firmas cuja intensa dinâmica inovativa se sustenta em sólidas competências técnicas, havendo em relação a elas uma expectativa de crescimento acelerado. No entanto, mesmo em países desenvolvidos, as evidências demonstram que ritmos de crescimento realmente elevados são mais exceção do que regra. No Brasil, o foco da maioria dos estudos sobre EBTs é diferente, concentrando-se em fatores que restringem seu sucesso, como experiência gerencial e disponibilidade de capital. Baseando-se em ampla pesquisa de campo e num indicador robusto de crescimento empresarial, este artigo pretende abordar a questão da expansão dessas empresas, analisando sua relação com elementos que as caracterizam, como grau de consolidação, inserção de mercado e apoio por políticas públicas. Entre os resultados, destacam-se uma taxa de crescimento que, embora muito variada, é geralmente expressiva - mediana de 15,3\% - e não se relaciona diretamente com a intensidade do apoio por políticas públicas.
\end{abstract}

Palavras-chave

Empresas de base tecnológica. Crescimento da firma. Política de ciência e tecnologia.

\section{Introdução}

Os últimos anos testemunharam uma mudança importante no contexto em que estão inseridas as empresas de base tecnológica (EBTs) brasileiras. Algumas empresas mais bem-sucedidas se aproveitaram do fortalecimento do mercado acionário e promoveram a abertura de seu capital.

Um bom exemplo seria o da Datasul. Fundada em 1978 e sediada em Joinville (SC), a empresa proclama-se líder entre as empresas brasileiras no setor de software de gestão. Realizou a abertura de seu capital em 2006 e tem procurado ampliar seu horizonte de crescimento com uma agressiva estratégia de aquisição de outras empresas. Apesar de ser um dos casos mais notórios de sucesso entre as EBTs brasileiras, o valor de mercado da Datasul situava-se, em maio de 2007, em torno de US $\$ 350$ milhões, uma pequena fração das cifras alcançadas por suas congêneres de países desenvolvidos, como a alemã SAP (US\$ 60 bilhões) e a americana Oracle (US\$ 110 bilhões).
Embora habitualmente caracterizadas por sua capacidade inovativa e seu potencial de crescimento, as EBTs no Brasil não costumam seguir estratégias que as posicionem como inovadoras primárias (PINHO et al., 2005), mas, ainda assim, sua dinâmica tecnológica frequentemente é capaz de dar sustentação à acumulação de importantes competências. A maioria dos estudos sobre as EBTs brasileiras têm privilegiado suas fases iniciais de criação, enfatizando muito menos a discussão sobre seu crescimento, temática que precisaria ser mais bem compreendida. Nesse contexto, o objetivo central deste artigo é analisar o crescimento das EBTs brasileiras, destacando a influência de variáveis como a idade, o acesso a instrumentos públicos de apoio e a inserção de mercado, e contrastando as especificidades desse tipo de empresa em um país em desenvolvimento com a experiência das EBTs nascidas e criadas em países que lideram mundialmente a dinâmica do progresso tecnológico. 
Este artigo está estruturado em cinco partes, além desta introdução. $\mathrm{Na}$ segunda parte, apresenta-se uma breve revisão da literatura pertinente, enfatizando o perfil do crescimento das EBTs nos países desenvolvidos, em especial uma tipologia que explora a diversidade interna desse tipo de empresa, e as características próprias desses empreendimentos em países desenvolvimento. $\mathrm{Na}$ terceira e quarta partes, são apresentados, respectivamente, os procedimentos metodológicos e os resultados empíricos para o crescimento da EBTs brasileiras. A quinta parte destaca as principais conclusões da pesquisa.

\section{Revisão da literatura}

\subsection{Características das EBTs}

A análise das características das EBTs é um dos pontos de partida para a compreensão da dinâmica de crescimento dessas empresas. Elas participam ativamente das mudanças tecnológicas, atuando, nos países desenvolvidos, em segmentos genéricos, cujas plataformas tecnológicas se destinam a múltiplos usos e geram mercados amplos, como atividades relacionadas à biotecnologia e à microeletrônica. Sem prejuizo desse posicionamento mais abrangente, muitas EBTs desses países operando, por outro lado, em mercados específicos e delimitados de pequena extensão - nichos de mercado -, como a prestação de serviços especializados.

Fontes e Coombs (2001), ao analisarem o caso da EBTs portuguesas, verificaram um conjunto de aspectos centrais da natureza dessas empresas que são geralmente observadas em muitos países em desenvolvimento, quais sejam nível tecnológico relativamente baixo, desenvolvimento de produtos para um grupo de clientes já estabelecido, dependência de tecnologia importada e atuação centrada no aperfeiçoamento de tecnologias. As EBTs em Portugal são vistas mais como agentes de difusão tecnológica do que como motores diretos de crescimento, isto é, a maior contribuição dessas empresas ao desenvolvimento tecnológico está no papel da aquisição, transformação e disseminação de tecnologia já existente dentro de redes de inovação.

Algumas das características verificadas para as EBTs de Portugal estão presentes nas firmas brasileiras. Segundo Pinho et al. (2005) e Côrtes et al. (2005), nos países em desenvolvimento as EBTs se particularizariam por serem empresas que (1) realizam esforços tecnológicos significativos e (2) concentram suas operações na fabricação de "novos" produtos, mas costumam realizar apenas inovações incrementais, provenientes da imitação, adaptação ou engenharia reversa.

No Brasil, a ênfase da maioria dos estudos sobre as EBTs recai mais sobre os fatores de sucesso do que em seu processo de crescimento. Um trabalho que discute essa temática é o de Carvalho et al. (1998), cuja pesquisa empírica abordou 47 EBTs dos estados de São Paulo, Paraná e Santa Catarina. Essas empresas foram criadas por empreendedores com nível universitário (91\%), boa parte dos quais com formação em engenharia (41\%) e pós-graduação (30\%). São empresas de pequeno porte (66\% são microempresas), estabelecidas há menos de cinco anos (54\%) e basicamente constituídas por grupos de sócios (60\%), sendo muito comum que os sócios façam parte da mesma família. Um problema frequentemente realçado na discussão sobre as EBTs brasileiras é a grande carência de recursos financeiros, já que as principais fontes, capital próprio ou empréstimos convencionais, são normalmente insuficientes para as necessidades de investimento, e as saídas de caixa destinadas ao pagamento de juros, resgates e amortizações são encargos muito onerosos para empresas jovens, que requerem substanciais influxos de capital durante os estágios iniciais de crescimento (PINTO, 1997). A burocracia das instituições responsáveis pelo fomento a essas empresas e a difusão restrita das informações sobre as linhas de financiamento disponíveis são outros obstáculos que no Brasil prejudicam a capacidade de as EBTs captarem recursos (PEREIRA, 2007).

\subsection{Potencial de crescimento das EBTs}

Alguns aspectos do crescimento das EBTs, como a geração de empregos, têm sido fonte de intenso debate em escala internacional. Tether (1999) estudou a questão da diversidade de crescimento entre as pequenas firmas inovativas e observou que estas não apresentavam um ritmo intenso de geração de emprego, criando, em geral, menos de 10 por ano.

Essa característica foi observada em países europeus, como França e Suécia, mas também nos EUA, tradicionalmente conhecido como país de crescimento rápido dessas firmas, através de spinoffs oriundos de grandes empresas e universidades. Westhead e Cowling (1995) observaram que as EBTs apresentam uma taxa de crescimento maior que muitas pequenas firmas não inovativas, embora Tether e Mansini (1998) tenham demonstrado que, ainda que isso de fato ocorra, o emprego criado por elas é altamente concentrado: 9\% das EBTs 
analisadas por esses autores foram responsáveis por $48 \%$ dos empregos gerados por toda a amostra por eles estudada.

Para Oakey (1991), a suposição de geração de empregos dessas empresas é altamente questionável. Ao contrário da crença de muitos países no grande potencial de crescimento das EBTs, Oakey (1991) considera que elas, de fato, não são uma "panaceia" para os problemas estruturais da economia. No entanto, destaca que a ênfase do debate sobre as EBTs na questão da geração de empregos contrasta com a costumeira indiferença em relação ao desempenho nesse campo das grandes empresas, em que processos de reestruturação muito custosos em termos de postos de trabalho são habituais.

Outro ponto que pode ser levantado em relação ao crescimento das EBTs se refere à sobrevivência dessas firmas. Nos estudos realizados em países desenvolvidos, as EBTs possuem uma taxa de sobrevivência mais elevada do que as pequenas firmas de caráter não tecnológico. Licht, Nerlinger e Berger (1995), citados em Storey e Tether (1998), analisaram as EBTs do setor industrial da Alemanha Ocidental e mostraram que a taxa de sobrevivência entre elas era sensivelmente maior do que para muitas empresas tradicionais. Resultados semelhantes foram encontrados por Westhead e Storey (1994) em seus estudos das EBTs no Reino Unido e por Santarelli e Sterlacchini (1996), para as empresas de alta tecnologia da ltália. Os resultados dessas pesquisas impõem uma qualificação importante à visão convencional de empreendimentos de alta tecnologia como sujeitos a riscos excepcionalmente elevados.

Ainda que sejam raros estudos sobre 0 crescimento dessas empresas em países em desenvolvimento, observa-se que o potencial de crescimento das EBTs parece ser quase sempre maior onde a disposição de concorrentes estrangeiros de operar no país por meio de importações diretas ou de estabelecimento de unidades de produção locais é relativamente baixa, uma vez que em mercados relacionais as empresas locais desfrutariam de vantagens de proximidade no relacionamento com os clientes (FERNANDES et al., 2000).

\subsection{Tipologia de EBTS}

Tether (1997) construiu uma taxonomia de EBTs que as classifica de acordo com a frequência, o alcance e o modo de inovação. No sentido aqui empregado, modo de inovação refere-se às diferentes ênfases em inovações de produto e processo e, particularmente, ao foco dos esforços inovativos - modificações incrementais, novo design ou novidades mais amplas. Num primeiro grupo, estariam firmas que se baseiam no conceito de projeto "oportunista". Elas se apoiam-se em ideias e conceitos vinculados a tecnologias já estabelecidas, desenvolvendo aplicações que alargam o escopo original da inovação. Como exemplo desse grupo, o autor apresenta estabelecimento de uma firma para produzir roupas à prova de água. Em geral, as EBTs desse tipo não possuem capacidades e habilidades técnicas específicas, podendo ser caracterizadas por uma intensidade tecnológica limitada.

Essas empresas frequentemente desenvolvem alternativas para mercados especializados e pequenos e, por essas alternativas não serem protegidas por patentes e não se basearem em um conjunto complexo de conhecimentos, a tecnologia desenvolvida pode se tornar altamente copiável. A fim de deter a imitação, estas firmas procuram minimizar os riscos de explorar uma tecnologia incerta, dirigindo seus conhecimentos para mercados já conhecidos.

Um segundo grupo de EBTs, ainda segundo Tether (1997), seria o das firmas baseadas em tecnologias realmente novas. Para elas, a ausência de rivais estabelecidos é muito benéfica, implicando que essas empresas não precisam competir com outras capazes de produzir os produtos que irão desenvolver. Por isso, a taxa de sobrevivência dessas firmas pode ser maior do que para aquelas baseadas no conceito de projeto, já que a base de clientes se dirigirá para a nova tecnologia como única opção de consumo disponível.

A natureza das novas tecnologias, entretanto, varia com o padrão e a definição dos mercados, diferenciando as empresas desse tipo entre as baseadas em tecnologias genéricas e as que se atuam em nichos de mercado. As firmas que se fundamentam em tecnologias genéricas são criadas com uma definição pouco nítida sobre o mercado a ser explorado, sendo muito comum entre elas o compartilhamento do conhecimento (muitas vezes codificável), através da cooperação com empresas e universidades, a fim de ampliar o seu grau de percepção do mercado e com o intuito de expandir suas capacidades tecnológicas. Nesse subgrupo, segundo Tether (1997), incluem-se muitas firmas de microeletrônica e biotecnologia.

De acordo com Bantel (1998), EBTs que se fundamentam em tecnologias genéricas tendem a apresentar um crescimento superior ao das empresas focalizadas em mercados específicos e a apresentar uma posição competitiva mais sólida. Já firmas que desenvolvem novas tecnologias para nichos de mercados do segundo tipo mostram uma forte tendência de se tornarem cativas de seus clientes, dada a atuação em linhas mais estreitas. 
0 terceiro grupo de empresas descrito por Tether (1997) é o das firmas baseadas em tecnologia consolidada de nicho de mercado. Essa categoria é formada por firmas que foram bem-sucedidas no desenvolvimento de tecnologias, mas que, devido à maturação de seus ativos tecnológicos, estabilizaram-se e apresentam um baixo crescimento. Elas buscam combinar os conhecimentos sobre as preferências de seus usuários com habilidades já estabelecidas para desenvolver novos produtos por meio de inovações incrementais. 0 principal risco enfrentado por elas advém das mudanças tecnológicas introduzidas por novas firmas, que podem destruir suas competências. Esse tipo de firma é comum nos setores de produção de máquinas, equipamentos médicos e cirúrgicos, softwares e instrumentos de precisão.

\section{Metodologia}

A análise empírica se baseou em uma amostra de empresas presentes na base de dados que o Grupo de Gestão da Tecnologia (GeTec) da Universidade Federal de São Carlos (UFSCar) construiu sobre EBTs numa pesquisa de campo que entrevistou presencialmente 117 empresas de 12 estados brasileiros durante os anos de 2003 e 2004. Com base no conceito de empresa de base tecnológica anteriormente referido (PINHO et al., 2005; CÔRTES et al., 2005), a base de dados é composta por 102 EBTs de diferentes setores industriais, dos quais os mais representativos são os setores de equipamentos médico-hospitalares, de automação e instrumentos de precisão e os serviços de informática. As informações disponíveis referem-se à formação da empresa, faturamento, market-share, estratégia de inovação, atividades de cooperação, recursos financeiros, dentre outras dimensões das atividades das EBTs.

0 crescimento das empresas foi avaliado pela taxa de variação real do faturamento (TVRF) ou, mais precisamente, a taxa média geométrica de crescimento anual do faturamento entre 1997 e 2002. 0 deflator utilizado foi o IPCA-IBGE. A taxa de crescimento do faturamento para um período de cinco anos representa uma medida do dinamismo de médio prazo das empresas, um indicador da tendência de crescimento das empresas menos sujeito à influência de oscilações conjunturais do que taxas de crescimento calculadas para períodos mais curtos. Não obstante, considerando as informações fornecidas pelas empresas, foi possível calcular esse indicador para apenas 38 das 102 EBTs presentes na base de dados.
Não se pode descartar a existência de algum viés de composição nessa amostra de 38 empresas. As empresas que reportaram o seu faturamento em 1997 e 2002 podem não ser representativas do conjunto de 102 EBTs. Do mesmo modo, embora a amostra de 102 EBTs tenha sido selecionada com a intenção de cobrir abrangentemente o universo das EBTs brasileiras, em especial no tocante à diversidade setorial e de localização geográfica, não há garantias de que a base de dados do GeTec seja estatisticamente representativa do conjunto das EBTs existentes no Brasil (PINHO et al., 2005).

Ainda assim, deve-se ressaltar que o conjunto de 38 EBTs que terão seu crescimento analisado neste artigo apresenta ampla diversidade interna. São empresas de dez estados diferentes, que, em seu conjunto, empregavam 2.755 pessoas e faturaram R\$ 334 milhões em 2002. Embora nenhuma dessas empresas possa ser considerada grande, a variedade de portes fica bem expressa pela diferença entre 0 faturamento médio de $\mathrm{R} \$ 8,9$ milhões e a mediana dessa variável, $\mathrm{R} \$ 1,9$ milhão.

\section{Resultados}

Neste tópico, as taxas de crescimento do faturamento das empresas serão abordadas segundo vários recortes analíticos. Serão procuradas evidências de associação entre o crescimento das empresas e variáveis como a origem da empresa, a experiência e a formação gerencial dos empreendedores, o padrão de inserção no mercado e a obtenção de apoio por políticas públicas.

\subsection{Origem da empresa e capacitação gerencial}

A caracterização do padrão de crescimento das EBTs pode inicialmente ser feita com referência à origem da empresa. A Tabela 1 mostra que, em média, as EBTs oriundas de spin-offs empresariais (19 empresas) cresceram mais do que as EBTs provenientes de instituiçõesacadêmicas (11 empresas) - universidades e institutos de pesquisa, o que pode ser verificado pelas taxas de crescimento anuais de 26,7 e $22,2 \%$ respectivamente. Dentro da categoria Outros, foram incluídas aquelas EBTs que possuíam origem do tipo mista ou que foram criadas por profissionais liberais. Disparidade ainda maior entre os dois tipos de empresa ocorre no faturamento: o nível de faturamento das EBTs acadêmicas mostrou-se significativamente inferior ao das EBTs empresariais - a diferença de faturamento médio entre elas esteve acima de 60\%. 
A Tabela 2 sugere que, conquanto a experiência em gestão influencie positivamente o crescimento das EBTs com origem empresarial, o crescimento dos spin-offs acadêmicos com experiência em gestão foi em média de 18\%, inferior ao crescimento médio daquelas EBTs de mesma origem que não apresentavam experiência prévia em gestão quando de sua formação (31,7\%).

De modo geral, porém, a média de crescimento das empresas fundadas por gestores experientes $(29,6 \%)$ é maior que a média de crescimento das empresas criadas por gestores sem experiência (24,2\%). Observe-se, aliás, que das 34 EBTs analisadas, 20 obtiveram capacidade gerencial exclusivamente por meio da experiência cotidiana, ao invés da realização de cursos profissionais em gestão.

A diferença entre as taxas de crescimento é bem maior quando o critério distintivo entre as empresas é a presença de fundadores com formação gerencial (crescimento médio de $34,1 \%$ ) e sem essa formação $(22,1 \%)$. Embora a diferença seja expressiva e estatisticamente significativa ao nível de $10 \%$ segundo o teste de diferença de médias de Mann-Whitney, a segmentação das empresas de acordo com a formação gerencial não deixa de confirmar a relevância da experiência em gestão para o crescimento das EBTs. Diferenças relativamente pequenas entre as taxas de crescimento de dois grupos de EBTs podem estar associadas a fatores diferentes daqueles que estritamente distinguem as duas categorias. Através de um teste de significância estatística da diferença das médias é possível verificar se a diferença pode ser explicada por fatores fortuitos. 0 teste não paramétrico de Mann-Whitney verifica a hipótese nula de igualdade das medianas de duas populações. Aplicando-se o teste ao nível de significância de 10\%, identificou-se diferença estatisticamente significante entre as taxas de crescimento de empresas fundadas por empreendedores com e sem formação gerencial, mas não para a diferença entre empresas cujos fundadores tinham experiência administrativa e aquelas cujos fundadores não tinham essa experiência. Primeiramente, uma ressalva deve ser feita quanto à categoria de empresas "sem experiência em gestão e com formação gerencial”. Esse grupo foi composto por apenas duas empresas, uma delas com uma taxa de crescimento de $83,0 \%$. Assim, a média de 55,2\% deve ser analisada com cautela, dada a baixa representatividade dessa categoria de análise. Uma categoria mais representativa no conjunto de EBTs

Tabela 1. Desempenho das EBTs por origem do empreendedor e faixas de idade das empresas.

\begin{tabular}{|c|c|c|c|c|c|c|c|c|c|c|}
\hline \multirow[b]{2}{*}{$\begin{array}{l}\text { Faixas de idade } \\
\text { (anos) }\end{array}$} & \multicolumn{3}{|c|}{ EBT empresarial } & \multicolumn{3}{|c|}{ EBT acadêmica } & \multicolumn{4}{|c|}{ Outros } \\
\hline & $\begin{array}{l}\text { TVRF } \\
\text { média* } \\
(\%)\end{array}$ & $\mathrm{N}^{* *}$ & $\begin{array}{c}\text { Faturamento } \\
\text { em } 2002 \\
\text { (R\$ milhões) }\end{array}$ & $\begin{array}{l}\text { TVRF } \\
\text { média } \\
(\%)\end{array}$ & $\mathrm{N}$ & $\begin{array}{c}\text { Faturamento } \\
\text { em } 2002 \\
\text { (R\$ milhões) }\end{array}$ & $\begin{array}{l}\text { TVRF } \\
\text { média } \\
(\%)\end{array}$ & $\mathrm{N}$ & $\begin{array}{c}\text { Faturamento } \\
\text { em } 2002 \\
\text { (R\$ milhões) }\end{array}$ & $\begin{array}{l}\mathrm{N}^{* * *} \\
\text { Total }\end{array}$ \\
\hline Até 5 & 69,4 & 4 & 4,3 & 78,2 & 1 & 0,4 & - & - & - & 5 \\
\hline De 5 até 10 & 31,2 & 6 & 53,0 & 31,9 & 4 & 11,6 & 29,2 & 4 & 7,3 & 14 \\
\hline De 10 até 20 & 5,3 & 4 & 45,3 & 6,9 & 5 & 25,4 & 44,1 & 1 & 0,5 & 10 \\
\hline Acima de 20 & 4,3 & 5 & 161,5 & 4,0 & 1 & 3,3 & 14,6 & 1 & 18,6 & 7 \\
\hline Total & 26,7 & 19 & 264,1 & 22,2 & 11 & 40,7 & 29,3 & 6 & 26,5 & 36 \\
\hline
\end{tabular}

*Taxa média anual de variação real do faturamento (1997-2002). **N: Número de EBTs. ***Das 38 empresas que relataram informações de faturamento, duas não responderam à questão sobre sua origem. Fonte: Elaboração própria.

Tabela 2. Distribuição das EBTs por capacitação prévia e origem dos empreendedores.

\begin{tabular}{|c|c|c|c|c|c|c|c|c|c|}
\hline \multirow[b]{2}{*}{ Discriminação } & \multicolumn{3}{|c|}{ Com experiência em gestão } & \multicolumn{3}{|c|}{ Sem experiência em gestão } & \multicolumn{3}{|c|}{ Total } \\
\hline & $\begin{array}{l}\text { TVRF* } \\
\text { média } \\
(\%)\end{array}$ & $\mathrm{N}^{* *}$ & $\begin{array}{l}\text { ldade } \\
\text { média }\end{array}$ & $\begin{array}{l}\text { TVRF } \\
\text { média } \\
(\%)\end{array}$ & $\mathrm{N}$ & $\begin{array}{l}\text { ldade } \\
\text { média }\end{array}$ & $\begin{array}{l}\text { TVRF } \\
\text { média } \\
(\%)\end{array}$ & $\mathrm{N}$ & $\begin{array}{l}\text { ldade } \\
\text { média }\end{array}$ \\
\hline \multicolumn{10}{|l|}{ Origem $^{* * * *}$} \\
\hline Empresarial & 33,5 & 11 & 12 & 17,3 & 8 & 15 & 26,7 & 19 & 13 \\
\hline Acadêmica & 18,0 & 2 & 14 & 31,7 & 6 & 12 & 22,2 & 8 & 13 \\
\hline Outro & 29,2 & 4 & 7 & 29,3 & 2 & 21 & 29,3 & 6 & 12 \\
\hline Total & 30,7 & 17 & 11 & 24,2 & 16 & 15 & 25,8 & 33 & 13 \\
\hline \multicolumn{10}{|l|}{ Formação gerencial ${ }^{* * *}$} \\
\hline Com formação gerencial & 30,6 & 12 & 12 & 55,2 & 2 & 6 & 34,1 & 14 & 11 \\
\hline Sem formação gerencial & 27,6 & 6 & 9 & 19,8 & 14 & 16 & 22,1 & 20 & 14 \\
\hline Total & 29,6 & 18 & 11 & 24,2 & 16 & 15 & 27,1 & 34 & 13 \\
\hline
\end{tabular}

*Taxa média anual de variação real do faturamento (1997-2002). ${ }^{* *} \mathrm{~N}$ : Número de EBTs. ***Para quatro das 38 empresas a base de dados não tem informações sobre formação em área gerencial e experiência prévia em gestão. ${ }^{* * * *}$ Para cinco das 38 empresas a base de dados não tem informações sobre formação em área gerencial e experiência prévia em gestão. Fonte: Elaboração própria. 
estudadas é aquela composta por empresas "com experiência em gestão e com formação gerencial”. Sua taxa média de crescimento é de 30,6\%. Por outro lado, empresas com experiência em gestão, mas sem formação gerencial também puderam obter um crescimento bastante expressivo (27,6\%). Essas informações sugerem que, nas EBTs em que a experiência em gestão está presente, a ausência de formação gerencial não constitui uma forte restrição ao crescimento.

\subsection{Grau de consolidação}

Na análise do grau de consolidação procurou-se verificar a relação que existe entre o ritmo de crescimento das EBTs e sua idade. A Tabela 3 mostra que o crescimento de 38 empresas da amostra atingiu a taxa média de 25,1\% ao ano, resultado bastante significativo para esse conjunto de firmas. Contudo, é grande a dispersão das taxas de crescimento em torno dessa média, de modo que a mediana delas é bem menor: 15,3\%. A disparidade encontrada na distribuição das taxas de variação do faturamento - seis das 38 empresas apresentaram crescimento acima de 50\% ao ano - é consistente com a avaliação de Tether e Mansini (1998) de que as EBTs de alto crescimento são relativamente pouco frequentes. Por outro lado, a idade das empresas está inversamente associada ao seu ritmo de crescimento, resultando num coeficiente de correlação de $-0,571$. Com efeito, duas empresas com taxas de variação real do faturamento superiores a 60\% apresentaram as menores idades da amostra.

Procurando traçar o posicionamento das EBTs brasileiras em termos próximos aos da tipologia proposta por Tether (1997), as 38 empresas foram divididas em empresas maduras e não maduras, adotando como parâmetros de corte as medianas da idade e da taxa de variação real do faturamento. A primeira categoria, a das empresas maduras, agrupa empresas com idade acima da mediana de 10 anos e crescimento abaixo da mediana de 15,8\% ao ano; já a outra engloba as empresas não maduras, associadas com idade abaixo da mediana ou alta taxa de crescimento, isto é, são consideradas não maduras tanto empresas que são jovens quanto aquelas que apresentam crescimento acima do usual, mesmo não sendo mais jovens (Figura 1). Tal definição para esta última categoria permite captar as diferentes trajetórias de amadurecimento da inserção de mercado, abrangendo não apenas empresas que são "jovens” em termos estritamente etários, mas também aquelas que conseguem sustentar um forte ritmo de crescimento por períodos de tempo mais longos.
0 crescimento das EBTs quase sempre se ampara na ausência de concorrentes em um mercado pouco explorado. Mas se as EBTs brasileiras chegam a obter crescimento rápido quando jovens, nada garante que em suas etapas posteriores serão tão bem-sucedidas: as restrições ao crescimento surgem porque a demanda em nichos costuma se esgotar rapidamente. Dado o porte pequeno, o ritmo de crescimento dessas empresas estaciona em um patamar proporcional às competências internas que lhes foi possível acumular. Essas limitações estruturais combinadas com outras de caráter institucional, como a escassez de financiamento que viabilize uma expansão continuada, configuram um quadro de crescimento travado para a maioria das EBTs no Brasil.

Uma alternativa que, em princípio, poderia possibilitar às EBTs brasileiras um horizonte mais amplo de crescimento seria o desenvolvimento de tecnologias "apropriadas” às condições brasileiras. Estratégias tecnológicas desse tipo, ao se voltarem para problemas e necessidades específicas de países em desenvolvimento, minimizariam a concorrência com empresas e tecnologias inovadoras originadas nos países desenvolvidos. Não obstante, a análise da base de dados mostrou que as EBTs pesquisadas estão, em sua maioria, muito pouco voltadas para o desenvolvimento de tecnologias desse tipo. Do conjunto de 102 empresas foi possível identificar apenas nove empresas que concentram suas atividades em tecnologias “apropriadas”. Sobressaem entre elas desenvolvimentos tecnológicos empregados na agroindústria, e em especial aqueles voltados ao processamento da cana-de-açúcar. De todo modo, o crescimento de EBTs que perseguiram esse tipo de posicionamento pôde ser medido somente para duas empresas. A taxa média de crescimento encontrada foi de apenas 1,2\% ao ano. 0 resultado deve ser analisado com cautela devido ao pequeno número de empresas analisadas. Essas duas empresas são essencialmente consideradas como empresas maduras, apresentando idade alta e baixo crescimento.

\subsection{Inserção de mercado}

Outra análise do padrão de crescimento das EBTs pode ser feita através de sua inserção de mercado. A Tabela 4 evidencia que 18 das 38 EBTs prestaram informação sobre o market-share (parcela de mercado) de 33 produtos. Esses produtos se caracterizam por serem bastante específicos, posicionando as empresas em segmentos de mercado bem delimitados. 
Tabela 3. Distribuição das EBTs por faixas de crescimento.

\begin{tabular}{|c|c|c|c|c|c|}
\hline \multirow{2}{*}{$\begin{array}{c}\text { Faixas de } \\
\text { crescimento } \\
(\%)\end{array}$} & \multicolumn{2}{|c|}{ Total por faixa } & \multirow{2}{*}{$\begin{array}{l}\text { ldade } \\
\text { média }\end{array}$} & \multicolumn{2}{|c|}{ TVRF* (1997-2002) } \\
\hline & $\begin{array}{l}\text { Número de } \\
\text { EBTs }\end{array}$ & $\begin{array}{l}\text { Faturamento em } 2002 \\
\text { (R\$ milhões) }\end{array}$ & & $\begin{array}{l}\text { Média } \\
(\%)\end{array}$ & $\begin{array}{c}\text { Mediana } \\
(\%)\end{array}$ \\
\hline$<0$ & 6 & 154,2 & 18 & $-7,2$ & $-5,6$ \\
\hline 0 a 5,0 & 3 & 6,7 & 20 & 2,8 & 3,4 \\
\hline 5,0 a 10,0 & 3 & 9,6 & 15 & 9,2 & 9,3 \\
\hline 10,0 a 25,0 & 13 & 93,4 & 14 & 15,5 & 14,7 \\
\hline 25,0 a 50,0 & 7 & 9,7 & 7 & 37,0 & 37,1 \\
\hline$>50,0$ & 6 & 60,8 & 6 & 83,3 & 80,8 \\
\hline Total & 38 & 334,4 & 13 & 25,1 & 15,3 \\
\hline
\end{tabular}

*TVRF: Taxa média anual de variação real do faturamento. Fonte: Elaboração própria.

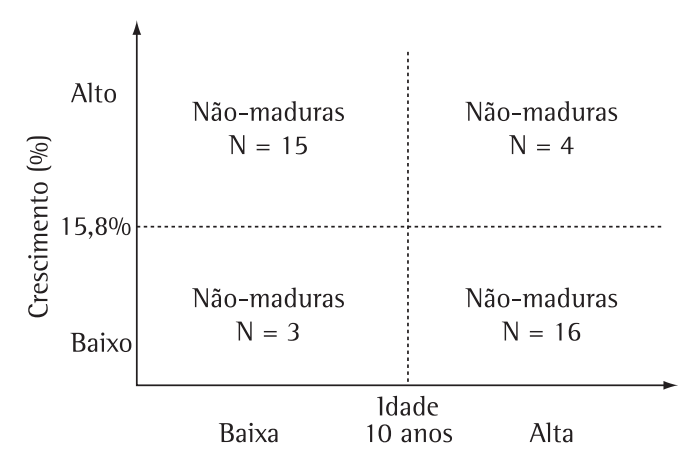

Figura 1. Grau de consolidação das EBTs pesquisadas.

Utilizando-se um indicador simples para se inferir o tamanho do mercado - o faturamento com o produto dividido pelo market-share -, é possível obter a distribuição dos mercados por faixas de tamanho. Na faixa de produtos com market-share superior a 50\%, situam-se $21 \%$ dos mercados. Esses sete produtos referem-se a mercados que têm uma extensão, em média, pouco superior a $R \$ 4$ milhões, mas nos quais a fatia de mercado detida pelas empresas alcança a média de $86 \%$. Já na faixa de market-share até 5\%, encontram-se 30\% dos mercados (10 produtos) cujo tamanho é, em média, de R\$28,5 milhões, mas com uma parcela de mercado em torno de 1,8\%. Em termos mais gerais, percebe-se que a fatia de mercado das EBTs estudadas tende a ser maior quando os mercados em que atuam são menores.

Esses resultados permitem concluir que a maior parte das EBTs da amostra efetivamente atua em nichos de mercado. Assim, essas empresas ocupam uma parcela de mercado bastante expressiva (em média, 28\%) dos mercados de seus principais produtos. Ademais, o exame do market-share por ramos de atividade mostrou que a parcela de mercado dos segmentos industriais é quase sempre superior a 50\%, enquanto a participação de mercado das empresas de serviços situa-se, no mais das vezes, nas faixas abaixo de $10 \%$.
Na faixa de empresas com market-share inferior a 10\%, estão EBTs com baixo market-share, mas com rápido crescimento. São basicamente empresas do ramo de serviços, principalmente de software. Por outro lado, na faixa acima de 50\%, encontram-se também EBTs com crescimento expressivo, mas em menor proporção que no ramo de serviços.

Em 90\% dos casos, as EBTs aqui investigadas atuam em mercados com extensão inferior a R\$ 50 milhões. Nesse contexto, a extensão limitada do mercado oferece oportunidade e, ao restringir o interesse de concorrentes potenciais, provê proteção, mas também limita seu horizonte de crescimento. Apenas duas empresas - com fatias de mercado em torno de 10\% - atuavam em mercados com extensão superior a R\$200 milhões, porém ainda assim inferior a R\$500 milhões. Mesmo que oferecendo oportunidades mais amplas, o posicionamento de mercado não deixa de configurar uma atuação em nicho. 0 rápido amadurecimento do mercado é decorrência dessa situação, que, nos casos de empresas mais bem-sucedidas, induz à adoção de iniciativas precoces de diversificação para dar vazão ao potencial de acumulação das empresas.

Com efeito, as maiores empresas da amostra adotaram estratégias de diversificação horizontal, introduzindo produtos novos, mas fabricados fundamentalmente com a mesma base de produção, em mercados bem próximos dos originais. As iniciativas de diversificação possibilitam às empresas prolongar o período em que as taxas de crescimento são relativamente altas. Observa-se também que, para as EBTs que atingiram um porte maior, abrem-se as oportunidades de crescimento por meio de aquisições. Assim, uma EBT da amostra, com sede no sul do Brasil e que atua em mercado com tamanho superior a R\$200 milhões, vem adquirindo empresas de software nacionais e de vizinhos sul-americanos, ingressando em novas áreas de atuação. Grande parte dessas operações ocorreu em 2007, atingindo, em conjunto, um 
Tabela 4. Faixas de market-share nos principais produtos.

\begin{tabular}{|c|c|c|c|c|c|}
\hline \multirow{2}{*}{$\begin{array}{c}\text { Faixa do } \\
\text { market-share } \\
\quad(\%)\end{array}$} & \multirow[t]{2}{*}{$\mathrm{N}^{*}$} & \multirow{2}{*}{$\begin{array}{c}\text { Vendas } \\
\text { do produto } \\
\text { (R\$ milhares) }\end{array}$} & \multirow{2}{*}{$\begin{array}{c}\text { Tamanho do } \\
\text { mercado } \\
\text { (R\$ milhares) }\end{array}$} & Participação (\%) & \multirow{2}{*}{$\begin{array}{c}\text { Market-share } \\
\text { médio } \\
(\%)\end{array}$} \\
\hline & & & & Simples & \\
\hline Até 5,0 & 10 & 410 & 28.507 & 30,3 & 1,8 \\
\hline 5,0 a 25,0 & 11 & 10.399 & 73.387 & 33,3 & 11,6 \\
\hline 25,0 a 50,0 & 5 & 5.825 & 15.013 & 15,2 & 35,0 \\
\hline 50,0 a 100,0 & 7 & 4.177 & 4.418 & 21,2 & 85,7 \\
\hline Total & 33 & 5.359 & 36.313 & 100,0 & 27,9 \\
\hline
\end{tabular}

${ }^{*} \mathrm{~N}=18$ empresas / 33 produtos. Fonte: Elaboração própria.

valor superior a $\mathrm{R} \$ 60$ milhões. Percebe-se, no entanto, que essa empresa passou previamente por um processo de abertura de capital, o que ampliou sua capacidade de investimento.

Esses fatos parecem indicar que o acesso a condições de financiamento mais favoráveis pode permitir a algumas EBTs a adoção de iniciativas para fugir da dinâmica "travada" de crescimento indicada por Pinho et al. (2005). Mesmo havendo dificuldades de estabelecer estratégias tecnológicas e mercadológicas consistentes frente à presença de concorrentes mais maduros, o crescimento por meio de aquisições, quando viável, alargaria o espaço para expansão por meio de movimentos mais agressivos de diversificação horizontal.

\subsection{Apoio por políticas públicas}

Das 38 empresas para as quais dispomos de informações sobre crescimento, 23 foram apoiadas diretamente por algum programa público de apoio direto à empresa. Essas empresas relataram que lhes foi concedido apoio em 56 projetos distintos. Dentre as diferentes modalidades de apoio, o Programa de Inovação Tecnológica em Pequena Empresa (PIPE) da Fapesp foi o mais citado, totalizando 16 projetos. Destacam-se também as bolsas RHAE (Capacitação de Recursos Humanos para Atividades Estratégicas) do CNPq, com oito projetos, e recursos da Finep (Financiadora de Estudos e Projetos), com 11 diferentes iniciativas de apoio, entre eles sobressaem os Fundos Setoriais e o Projeto Inovar.

A análise da taxa de crescimento não evidenciou um quadro de crescimento elevado para empresas apoiadas por alguma modalidade de política pública. 0 crescimento do faturamento das 23 empresas apoiadas foi em média de 20,9\% ao ano, situando-se abaixo tanto dos 31,5\% das empresas não apoiadas quanto dos $25,1 \%$ encontrados para o crescimento médio de toda a amostra. Não obstante, a análise da mediana mostra que as empresas apoiadas cresceram um pouco mais que as EBTs não apoiadas.
A Tabela 5 apresenta resultados retirados do conjunto da base de dados e não apenas das 38 empresas para as quais se pôde calcular a TVRF. Em um pequeno grupo de EBTs apoiadas, composto por quatro empresas, esses recursos assumem um valor muito expressivo, representado por uma relação média entre apoio e faturamento de $479 \%$. Para outras nove empresas essa relação foi de $72 \%$. Note-se que essas EBTs que receberam apoio mais vigoroso não são empresas recém-criadas, para as quais um ratio elevado entre apoio e receita de vendas seria justificável pelo estágio pré-operacional e consequente baixo faturamento.

$\mathrm{Na}$ análise da relação entre o montante obtido e o faturamento em 2002 é preciso considerar que pode haver na amostra de empresas certo viés em favor de empresas com vínculos com instituições de fomento. Por outro lado, é necessário reconhecer que os apoios declarados pelas empresas não esgotam o conjunto de apoio que elas efetivamente obtiveram, já que a questão respondida pela empresa não pretendia esgotar os mecanismos de apoio a que as empresas tiveram acesso.

Entre as 23 EBTs que prestaram informações que permitem calcular sua taxa de crescimento e, adicionalmente, declararam haver obtido apoio de programas de políticas públicas, a relação apoio/faturamento é bem maior para aquelas cujos fundadores são oriundos de instituições acadêmicas (148\%) do que para aquelas em que os fundadores são provenientes de empresas (27\%). Pode-se supor que o fato de essas EBTs captarem mais intensamente recursos públicos se deva a sua própria origem. A maior capacidade de elaboração de projetos e a tendência das instituições de fomento de supervalorizarem critérios acadêmicos em sua avaliação implicariam vantagens na obtenção de recursos pelos spin-offs acadêmicos. 0 vínculo existente entre algumas empresas e as instituições de fomento preponderaria sobre as necessidades e oportunidades que outras empresas apresentariam. 
Tabela 5. Distribuição das EBTs segundo a relação entre apoio e faturamento.

\begin{tabular}{cccc}
\hline $\begin{array}{c}\text { Apoio / } \\
\text { faturamento } \\
(\%)\end{array}$ & $\mathrm{N}^{*}$ & $\begin{array}{c}\text { Ratio médio** } \\
(\%)\end{array}$ & $\begin{array}{c}\text { ldade } \\
\text { média }\end{array}$ \\
\hline Até 5,0 & 5 & 2,0 & 17 \\
5,0 a 10,0 & 2 & 6,5 & 16 \\
10,0 a 25,0 & 7 & 17,5 & 8 \\
25,0 a 50,0 & 5 & 31,9 & 11 \\
50,0 a 100 & 9 & 72,4 & 7 \\
Mais de 100 & 4 & 479,1 & 8 \\
Total & 32 & 89,8 & 10 \\
\hline
\end{tabular}

*N: Número de EBTs.**Razão entre o valor atualizado do apoio direto obtido e o faturamento no ano anterior à pesquisa (2002) Fonte: Elaboração GeTec (UFSCar).

Além disso, há empresas que são juridicamente criadas por pesquisadores acadêmicos e conseguem obter financiamento público, mas não chegam a se constituir empresas no sentido estrito, não dispondo de instalações físicas e funcionários que deem sustentação a atividades efetivas de produção. Essas empresas poderiam ser caracterizadas como sendo EBTs-laboratório, ou seja, empresas fundadas por pesquisadores com origem acadêmica, que fazem da firma uma extensão do seu ambiente e atividade na universidade. Esse resultado está de acordo com o sugerido por Pinho et al. (2005), que aponta que empresas com uma rede de relações mais rica podem se posicionar melhor na disputa por recursos provenientes de instituições públicas.

\section{Conclusões}

0 crescimento das EBTs no Brasil manifesta-se de forma variada, existindo diferenças de desempenho associadas a variáveis como idade e inserção no mercado.

0 market-sharedas EBTs estudadas caracteriza-se por ser bastante expressivo. Atuam essencialmente em nichos de mercados, com extensão, quase sempre, inferior a R\$ 50 milhões. Como consequência, o crescimento horizontal nesses mercados torna-se rapidamente limitado, passando as EBTs a depender de processos de diversificação, principalmente de lançamentos de produtos que possam ser fabricados a partir da base tecnológica preexistente.

A constatação de que a maioria das EBTs investigadas obteve algum tipo de apoio por políticas públicas indica o aproveitamento de oportunidades oferecidas pelas agências de fomento em seus diferentes programas. No entanto, a obtenção desses apoios não parece estar vinculada a uma maior taxa de crescimento: a média de crescimento das 23 EBTs apoiadas foi de 20,9\%, índice abaixo dos $31,5 \%$ encontrados para as 15 EBTs não apoiadas. Além disso, em um pequeno grupo de EBTs de origem acadêmica, a relação recursos públicos/ faturamento foi muito elevada, sugerindo um viés institucional em favor de empresas com esse tipo de origem. Mais ainda, como um desdobramento mais geral do trabalho de pesquisa, outro tipo de EBT foi identificado, o das EBTs-laboratório, empresas fundadas por pesquisadores com origem acadêmica, que fazem da firma uma extensão da sua atuação na universidade, sem configurar uma opção decidida pela atividade empresarial.

De modo geral, pode se afirmar que o crescimento verificado para o conjunto das 38 empresas analisadas não foi desprezível, apontando a existência de oportunidades de acumulação de capital expressivas. Uma taxa anual de crescimento do faturamento que, em termos de mediana, alcança 15,3\% não é baixa, mesmo que não reflita adequadamente aqueles casos mais bem-sucedidos, nos quais o ritmo de crescimento atinge valores bem acima desse patamar. De todo modo, as condições típicas de inserção das EBTs brasileiras em nichos de mercados de pequena extensão e a adoção de estratégias tecnológicas que não costumam conduzir a inovações primárias são obstáculos à replicação no Brasil das histórias de transformação de pequenas empresas de base tecnológica em grandes firmas capazes de liderar em escala internacional os mercados que elas mesmas formaram.

\section{Referências}

BANTEL, K. Technology-based, "adolescent" firm configurations: strategy identification, context, and performance. Journal of Business Venturing, v. 13, p. 205-230, 1998.

CARVALHO, M. M. et al. Empresa de base tecnológica brasileira: características distintivas. In: SIMPÓSIO DE GESTÃO DA INOVAÇÃO TECNOLÓGICA, 20, 1998, São Paulo. Anais... São Paulo: [s.n], 1998. p. 461-74.

CÔRTES, M. R. et al. Cooperação em empresas de base tecnológica: uma primeira avaliação baseada numa pesquisa abrangente. São Paulo em Perspectiva, v. 19, n. 1, p. 85-94, 2005.

FERNANDES, A. C. et al. Potencialidades e limites para $o$ desenvolvimento de empresas de base tecnológica no Brasil: contribuições para uma política industrial. São Carlos: Universidade Federal de São Carlos, 2000. Programa Políticas Públicas. Relatório de Pesquisa FAPESP.

FONTES, M.; COOMBS, R. Contribution of new technologybased firms to the strengthening of technological capabilities in intermediate economies. Research Policy, v. 30, p. $79-97,2001$ 
LICHT, G.; NERLINGER, E.; BERGER, G. New technologybased firms in Germany: a survey of the recent evidence. Research Policy, v. 26, n. 9, p. 1005-1022, 1995.

OAKEY, R. High technology small firms: their potential for rapid industrial growth. International Small Business Journal, v. 9, n. 4, p. 30-42, 1991.

PEREIRA, R. C. C. Os instrumentos de financiamento às empresas de base tecnológica no Brasil. 2007. Dissertação (Mestrado em Engenharia de Produção) - Departamento de Engenharia de Produção, Universidade Federal de São Carlos, São Carlos.

PINHO, M. et al. Empresas de base tecnológica. São Carlos: Universidade Federal de São Carlos, 2005. FUNDUNESP/ FINEP/DPP, Relatório de Pesquisa.

PINTO, L. F. G. Capital de risco: uma alternativa de financiamento às pequenas e médias empresas de base tecnológica - o caso do Contec. Revista do BNDES, n. 7 , p. 151-184, 1997.

SANTARELLI, E.; STERLACCHINI, R. Analyzing literature based innovation output indicators: the italian experience. Research Policy, v. 25, p. 689-711, 1996.
STOREY, D. J.; TETHER, B. S. New technology-based firms in the European Union: an introduction. Research Policy, v. 26, n. 9, p. 947-971, 1998.

TETHER, B. S. Growth diversity amongst innovative and technology-based new and small firms: an interpretation. New Technology, Work and Employment, v. 12, n. 2, p. 91-107, 1997.

TETHER, B. S.; MANSINI, S. Employment creation in small technological and design innovators in the UK during the 1980's. CRIC, n. 10, p. 353-70, 1998.

TETHER, B. S. Small firms and employment creation in Britain and Europe: a question of expectations. CRIC, n. 2, p. 1-9, 1999.

WESTHEAD, P.; Cowling, M. Employment change in independent owner managed high technology firms in Great Britain. Small Business Economics, v. 11, n. 12, p. 111-140, 1995.

WESTHEAD, P.; STOREY, D. J. An assessment of firms located on and off science parks in the United Kingdom. London: HMSO, 1994.

\title{
Analysis of growth of technology-based firms in Brazil
}

\begin{abstract}
Technology-Based Firms (TBFs) are companies with intensive innovation dynamics based on technical competences, and for which high growth rates are expected. Nevertheless, even in developed countries, the evidence suggests that significantly high growth rates are more the exception than the rule. In Brazil, most studies on TBFs focus on factors that limit their success, such as managerial experience and capital availability. Based on extensive field research and on a reliable enterprise growth rate indicator, this article aims to evaluate the expansion of those firms, analyzing its relation to key elements such as degree of consolidation, market insertion, and public policy support. We found a growth rate which, although widely varied amongst firms, was significant and was not directly related to the amount of public policy support.
\end{abstract}

\section{Keywords}

Technology-based firms. Firm growth. S\&T policy. 